${ }^{1}$ College of Education, Qatar University

${ }^{2}$ National Center for Educator Development, College of Education, Qatar University

*Email: Michaelhr@qu.edu.qa http://dx.doi.org/

10.5339/nmejre.2013.3

Submitted: 10 December 2012 Accepted: 13 May 2013

(C) 2012 Romanowski, Al-Hassan,

licensee Bloomsbury Qatar

Foundation Journals. This is an open access article distributed under the terms of the Creative Commons Attribution License CC BY 3.0, which permits unrestricted use,

distribution and reproduction in any medium, provided the original work is properly cited.

\section{Arab Middle Eastern women in Qatar and their perspectives on the barriers to leadership: Incorporating transformative learning theory to improve leadership skills}

Michael H. Romanowski ${ }^{1, \star}$, Fatma Saeed Al-Hassan ${ }^{2}$

\section{ABSTRACT}

The development of leaders is a high priority on the national agenda for countries around the world especially in fast-developing regions such as the Middle East. Qatar seeks to support and develop Qatari men and women in the labor force while attracting qualified expatriate workers, many of these individuals serving as leaders in various aspects of society. In particular, the increase in women as leaders in such vital fields as education raises important issues that women face in order to be effective leaders. The central focus of this research project is to explore the perspectives of Middle Eastern Women living in Qatar regarding the barriers they might face and then use Transformative Learning Theory (TLT) to produce strategies that can be integrated into educational leadership programs in order to enable women to develop complex understandings of the circumstances and structures that present barriers to leadership. The sample for this study was drawn from Middle Eastern Women living in Qatar who are in leadership positions. Forty-one participants completed a ten-question, open-ended survey posted on Survey Monkey (it was made available in both English and Arabic) regarding their perspectives on the barriers facing them as women in leadership positions. Upon completion of the data analysis, 10 semi-structured interviews were conducted based on the emergent survey themes. Findings from survey responses and interviews support previous research findings regarding barriers faced by women in the Middle East. Transformative Learning Theory is used to offer ways to prepare women for leadership, because it fosters certain emancipatory knowledge essential to personal and national development. 


\section{BACKGROUND}

The development of leaders is a high priority on the national agenda for countries around the world, especially in fast-developing regions such as the Middle East. For example, Qatar, a small nation located on the Arabian Gulf, understands that "Qatari women (females with Qatari citizenship) will likely play a key role in the country's economic future" (p. 1). ${ }^{1}$ However, because of the growing population and the low percentage of the Qataris compared to the expatriate population, ${ }^{2}$ there is a need for expatriate women to assume various leadership positions.

In particular and relevant to this paper, Qatar's massive educational reform, Education for a New Era (EFNE), has resulted in the opening and operation of approximately 175 independent schools in Qatar and within Qatar's independent school system, there are a high percentage of female schools and male schools from kindergarten to sixth grade that are lead by females. Because of this increase of schools, there is a need for qualified leaders to implement EFNE, requiring greater participation of women in leadership positions. Although Qatar has made important political, educational and social changes that expand opportunities for women, there are still barriers to women holding leadership positions that need to be named and examined.

In what follows, we report findings from an exploratory, qualitative study designed to examine Middle Eastern women's perspectives on the barriers to leadership. These perspectives are presented and then examined using Transformational Learning Theory (TLT) as a theoretical lens in order to offer recommendations for Graduate Educational Leadership programs. This methodology was designed to provide women with a language that enables them to develop complex understandings of the circumstances and structures that present barriers to leadership.

\section{Barriers Facing Middle Eastern Women in Leadership}

Felder and Vuollo ${ }^{1}$ point out that in Qatar, women are better educated than men on average. They are entering the labor force in increasing numbers, and the number of Qatari women holding important leadership positions is growing. Currently, Qatari women successfully serve or have served in high leadership positions demonstrating that Qatari females can successfully hold leadership positions and at the same time meet family obligations. ${ }^{1}$

However, leadership positions for women in Qatar are limited. The ${ }^{3}$ points out that in 2009 only 3 percent of economically active Qatari women had leadership posts with the number ranging from two percent to four percent over the past years. "Although women have higher average educational attainment level than men, there appears to be a "glass ceiling" in employment and promotion for women" (p. 175). This is not only the case for Qatari women. Metcalfe et al. ${ }^{4}$ argue for non-citizens, foreigners' prejudice against women makes them ineffective as managers and companies are often hesitant to send female managers on international assignment because of the prejudiced against female leaders. Therefore, it can be inferred these barriers are found for women all over the Middle East because these leadership positions are inescapably entrenched in a male-dominated Arab society.

Noteworthy is that Middle Eastern women probably face similar constraints experienced worldwide by women but these are "compounded in an Arab Middle Eastern context by religiously and culturally defined attitudes and practices" (p. 583). ${ }^{5}$ In addition, the Arab world is not a homogeneous region. There is no single prototype for Arab women, and these barriers are relative to a particular part of the Arab world. With that in mind, there are several areas that we would like to examine that are relevant to improving the women's role in the workplace.

First, Arab women are considered by some as the upholders of cultural values and traditions. Since Arab culture places importance on motherhood and domesticity, ${ }^{6}$ the understanding of Arab women is very traditional, emphasizing reproductive functions. ${ }^{5}$ Thus many Arab women are reluctant to leave these caretaker roles in pursuit of leadership positions. If attained, women face many challenges in terms of devoting the needed time and energy to be successful. Intensifying these values are the traditional forces of tribalism, which reinforce these views and lead to a reverting trend in women's rights and their participation in leadership roles.

Second, the World Bank's traditional gender paradigm developed to explain the low rates of women in the labor force provides some insight into the barriers Arab women face. The World Bank argues gender roles are shaped by a traditional gender paradigm that assumes that the most important contribution women can make to family and society is homemakers and mothers. The paradigm is based on the centrality of the family, rather than the individual, as the main unit of society. The emphasis on the family is seen as justification for equivalent, rather than equal, rights in which men 
and women are presumed to play complementary roles. Both men and women use the family as an important cultural asset. Second, there is the assumption that the man is the sole breadwinner of the family. Third, a code of modesty exists, under which family honor and dignity rest on the reputation of the woman. This code imposes restrictions on interactions between men and women. Last, there is an unequal balance of power in the private sphere that affects women's access to the public sphere. This power difference is anchored in family laws (p. 10). ${ }^{7}$ This paradigm presumes that the man has a responsibility to support and protect his wife and family, and this in turn justifies his full authority and control over his wife's interactions in the public, ${ }^{8}$ often limiting the woman's opportunities for leadership positions to those where females are segregated from men.

Finally, the concept of gender draws heavily on Islamic religion and a combination of Islamic values and patriarchy, placing the man at the head of the family and society. This has a profound impact on the status of Arab women's patterns of labor and leadership. ${ }^{5}$ Patriarchy in this context is "a combination of patriarchy, conservative religious interpretations and cultural stereotyping that have built a very strong psychological barrier among Arab populations regarding women's participation in the public sphere" (p. 55). ${ }^{8}$ According to, ${ }^{9,10}$ Islam has been manipulated by a patriarchal society to legitimize discrimination against women, and the real issue for women is the patriarchal structure that extends throughout all levels of Arab society serving as a major force hindering Arab women's advancement.

In spite of the family, cultural, religious and societal barriers, it can be argued that women have made important progress in the last few decades ${ }^{11}$ in terms of securing leadership positions in various public and private institutions. Nevertheless, when Middle Eastern women secure leadership positions, they still must face the barriers mention above in addition to the shortcomings within institutional and legal frameworks. Only when women are empowered as leaders who are astutely aware of the hegemonic elements of societal and cultural values and possess the ability to challenge and change the thinking behind these values can transformation take place.

\section{PURPOSE OF STUDY}

The purpose of this study is to examine the barriers Middle Eastern women face in leadership positions and then illustrate how Transformative Learning Theory (TLT) can be used to offer ways to prepare women for leadership, because TLT fosters certain emancipatory knowledge essentials for personal and national development. ${ }^{12}$ At the micro level, transformative learning is characterized by the development of a critical consciousness around personal assumptions, while at the macro level, transformative learning contributes to broader social progress by encouraging dialogue and constructing critically informed understandings of social assumptions. ${ }^{13}$ Specifically, this study centers on the development of educational leaders who are responsible for implementing Qatar's massive educational reform, Education For a New Era, by developing ways TLT can be integrated into a Graduate Educational Leadership Program.

\section{METHODS}

In this study, leadership is broadly defined as having obtained a leadership position. Thus, the sample for this study was drawn from Middle Eastern Women in leadership positions, both in and out of educational settings. For this study, 125 Middle Eastern women who were known to have leadership positions in Qatar were sent emails and asked to participate in this study. These women were selected from a list generated by the researchers based on their experience working in Qatar, information from Internet searches and names that were provided by colleagues.

Follow-up emails were sent to individuals, and 41 questionnaires (33\% return rate) were completed and analyzed. Of the 38 respondents, 27\% (11) held Graduate Degrees, 69\% Bachelor Degrees (28), 2\% (1) Associate Degree (1) and 2\% (1) a high school degree. The participants' leadership experiences ranged from several months to 14 years with an average of 4.67 years of leadership experience for all participants. Because of the gender segregated aspect of Qatari culture, 15 of the respondents' leadership positions limited them to supervising females while the remaining respondents supervise both male and females in varying percentages.

The research questions are as follows:

1. From the perspective of Middle Eastern women living in Qatar, what are the barriers they face regarding leadership positions? 
2. Do Middle Eastern women living in Qatar face prejudice or unfair treatment in pursing or while in leadership positions?

3. What do Middle Eastern women in leadership positions in Qatar suggest to overcome these barriers?

4. How can Transformative Learning Theory be used to make women aware of their roles as leaders?

An open-ended questionnaire was designed to examine respondents' experiences and the barriers they face as female leaders in both educational and non-educational settings (See Appendix A). Participants were asked to complete a ten-question, open-ended survey posted on Survey Monkey (made available in both English and Arabic) regarding their perspectives on the barriers facing them as Arab women in leadership positions. The instruments were initially written in English then translated into Arabic and judged for the quality of the translations by bilingual native Arabic speakers. Face validity was obtained by having two bilingual professors who are well qualified in conducting research examine the questionnaire and determine if the Arabic translation was accurately asking participants to explain the barriers that they face. Regarding the exploratory nature of the study, open-ended questions were more appropriate for the purposes of this research. While closed questions allow for the collection of data that can be analyzed statistically and yield generalizable results, the narrative comments from open-ended questions provide a forum for explanations, meanings and new ideas that describe a phenomenon as lived and perceived by the respondent. ${ }^{14}$

In order to expand the sample and check findings, ten female leaders who did not complete the survey were identified based on the researchers' knowledge of females currently holding leadership positions in Qatar. The participants included an academic vice principal, school principal, leader at the SEC, department chair, professional development specialist, director of external relations, two heads of public relations, a head of department at the supreme education council and a chair of a board of trustees.

The self-described leadership styles of all participants would be categorized under the following respondent terms: democratic, transformational, supportive, collaborative, situational, participative, shared and leading by example. Although, we would like to point out that these are self-reported, and from our experiences teaching and researching in Qatar, we would argue that these descriptions are from the leaders' perspective and may not reflect the thoughts of those that they lead. This issue is, however, beyond the scope of this paper.

\section{ANALYSIS}

The responses were grouped according to each survey question. Responses to each open-ended question were examined in the context of the research questions. During the analysis, several themes emerged. Themes were then content analyzed, and relevant quotes were integrated into various themes in order to support or refute particular findings. The rationale was to provide an accurate account of the participants' perceptions of the barriers toward women in leadership positions. Upon completion of the data analysis, several interview questions were developed based on the emergent survey themes (See Appendix B), and semi-structured interviews were conducted in order to gain additional information and also to either refute or support the data from questionnaires. Data gained from survey responses and interviews were used to develop recommendations for graduate Educational Leadership programs in the Middle East. All quotes that are included in this paper were edited to improve the English but were not altered in any way that changed the meaning or context.

\section{RESULTS}

Although one could argue that these barriers and issues are common for women worldwide, or at least regionally, and the degree to each barrier is relative to the particular country, we present these findings based on the female respondents' perspective. To report these findings accurately, we present results from the questionnaires followed by results from the semi-structured interviews.

\section{FINDINGS FROM QUESTIONNAIRES}

Findings from the questionnaire responses indicated that $76 \%$ (31 participants) believed there were barriers that women faced in leadership positions and these findings indicated that these barriers centered on three areas. 


\section{Arab Traditions, Culture and Perceptions of Women}

The first barrier to leadership for Arab Middle Easter women as described by the 59\% (24 respondents) of the participants is the Arab traditions and culture. The following written response by one participant illustrates this barrier. She writes:

Yes there are barriers like culture, religion, the thinking of Arab men. Arab men do not encourage women to be leaders and manage people, especially managing men. This is taught when they are young, e.g., the brother is always responsible for sisters, and the father is responsible for his daughters, sisters, wives. In Islam, when the woman wants to go Hajj in Saudi Arabia, she must have Mahram and this man must be her father, brother or uncle. So how can she be a leader?

Arab traditions and culture described by these women play a vital role in how they are perceived by culture, especially men. One woman wrote: "The conservative nature of the Arab society in general is a barrier in itself." This is echoed by participants who wrote: "Arab culture assumed that men are definitely better leaders," and "the barriers include how men perceive women; for example, women cannot talk to men without others being present... how can you be a leader facing this issue?"

Another participant sums up this view of women writing "the society accepts the man as a leader and not a woman ... this is what men and some women think. The woman needs a man to protect her and to help her think about decisions."

The perception of women emerging can become a barrier for some women regarding leadership. Thinking was exposed in the following participants' statements:

“[My] husband's jealous if I work with men."

"Men do not like if women are leaders and if a woman has a better position than them."

"Men do not trust women."

"The man does not prefer to be led by a woman, and no one will marry her." and

"Both men and women think that women are not wise in problem solving and quick decisionmaking."

All statements reflect how culture and traditions have shaped Arab thinking and the perception of women in leadership positions. Finally, the idea that women cannot have the final say was mentioned in the following statement: "One barrier I observed is the inability for women to give the final decision or judgment on an issue."

\section{Patriarchal Structure of the Family}

The second barrier described by participants is the Arab family that centers not only on the responsibilities of Arab women but also a particular perception of women. From these participants' responses, 52\% (21 participants) indicated that family was a barrier that women faced in leadership positions. One respondent wrote: "The most important barrier is a woman's family commitment." This is supported by another participant's written statement about the responsibilities within the family, especially for married women. In some Arab societies, the image of the woman is always associated with her role in the family and not her role in society. I mean, the concept of a woman is identified more with being a wife and mother than being anything else.

This respondent points out that the domestic and maternal view of the women can play a barrier in not only a woman's performance as a leader but also her ability to pursue leadership positions. One respondent supported this when she wrote, the "husband does not like his wife to be in a leadership position but should take care of the home and children." Another woman supporting this argument wrote: "Women in the Middle East are expected to take care of the household and the kids and this could be a hindrance to their performance and role in the workplace."

Several respondents pointed out that this barrier is more "relaxed" with unmarried women. For example one respondent wrote "there are some families who accept the daughter to be a leader especially if she is not married" while another gave the following answer to the issue of family as a barrier: "It could be the responsibilities within family, especially for married women." Still, another participant stated: "There are many Arab families who are not as oppressive towards women." All this points to the idea that if the woman is married or single and the mentality of the family is more "liberal," family is less of a barrier for these women seeking and performing in leadership positions. 


\section{Particular Interpretations of Islam}

Forty percent of the participants (15 respondents) mentioned interpretations of Islam as a barrier to leadership for women. Participants wrote:

"The way men interpret Islam is the cause of the barrier."

"In the beginning of Islam, there were many women in leadership positions but that has changed... so we need time for women to be accepted in leadership positions,"

"The religious rules that are controlling women and their communications with the community."

These comments indicate that particular contemporary interpretations of Islam played out in society leads to barriers for women and leadership. For example, one participant wrote: "In Islam, women should cover their faces in front of other men ... a woman cannot lead a man, and Islam says that the place of a woman is home." Additional comments include: "Islam creates male dominancy," and "Islam has some men believing that they cannot accept to be led by a woman."

Clearly these statements illustrate barriers to any type of leadership positions outside gendersegregated institutions. Finally, there were $24 \%$ (10 participants) who believed that there were no barriers for women in leadership positions in Qatar but that barriers were evident in other Arab countries. Several participants argued that women held high leadership positions in Qatar and several cited Sheikha Mozah bint Nasser Al Missned (the second wife of Sheikh Hamad bin Khalifa Al Thani, Emir of the State of Qatar) and Shaikah Al-Mahmoud who served as minister of education as evidence that barrier to women in leadership does not exists.

\section{Prejudice and Unfair Treatment}

Regarding respondents' viewpoints of prejudice and unfair treatment of women in leadership positions, $34 \%$ (14 respondents) indicated that there was some prejudice against women in leadership positions and 40\% (16 respondents) believed that women leaders faced some unfair treatment. Several tie the prejudice and unfair treatment to the culture. One participant wrote: "I don't know any specific personal experiences but I think that Arab women do not get the same opportunities and treatment as women in the Western society because of the cultural reasons mentioned."

Another statement by a participant centers on how the culture plays a role in prejudice and unfair treatment. She wrote: "Yes in many Arab countries women are not allowed to take higher positions especially that required long working hours and traveling which is really unfair." Several other participants' responses are directly linked to the culture: "Women are always facing prejudice [have] to work twice as much as a man ... they must double their efforts to prove their ability," and "There is no mercy for women especially when they have circumstances like being pregnant and being responsible for her children." As you can see, most of the reasons for unfair treatment can be directly linked to the previous discussion regarding barriers women face.

Other participants linked the unfair treatment to other issues. Additional reasons included being nonQatari and Qatarization (the identification and development of quality, competent Qataris to assume permanent positions in public and private sector jobs). One participant wrote: "I think Qatarization plays a role in the unfair practices and treatment of women," while another stated: "I think most of the unfair treatment is for being non-Qatari. For example while recruiting there are some factors of nepotism among the Qataris." Second, prejudice and unfair treatment is linked to early concerns regarding stereotypes as illustrated by this participant's comment: "women are stereotyped as the weaker gender." Third, several participants indicated that women in leadership positions was purely for a public image that Qatar wants to portray and one participant wrote: "A woman in a leadership position is only for an image and positive publicity for Qatar."

Finally, 32\% (13 participants) of the participants indicated that there was no prejudice toward women in leadership, and 20\% (8 participants) thought the treatment of female leaders was fair. Written comments by participants illustrate this thinking are as follows:

"I don't think there is any prejudice. If they have the required competence, and there are no Qataris for this position, you can take these positions."

"Here in Qatar you can be a leader if you deserve the position, even if you are female."

"We have female ministers and judges and so on."

There are two lengthy comments worth citing because of the thinking presented. Participants wrote: 
"If an Arab woman reaches the position by her efforts, she will find support and assistance from everyone. The community perception has been changed toward a woman's abilities... our Arab society boasts about women leaders who compete with men."

“I don't think there is prejudice toward women in Qatar. On the contrary, the most commanding figure is Sheikha Mozah, who has a global role and therefore the leadership positions in Qatar are available to women."

These two participants raise interesting points. The first argues that merit alone will provide support and assistance and that merit itself reduces gender prejudice and unfair treatment. Accordingly, merit combined with a changing culture that boasts about successful women eradicates prejudice and unfair treatment. The second statement builds on the changing society and culture and argues that because the Emir's wife holds a high position there is no or little unfairness and prejudice toward women.

\section{FINDINGS FROM INTERVIEWS}

The ten women who participated in interviews agreed that the barriers emerging from the questionnaire do exist within the culture, but for these women, it seemed that the barriers were not applicable to their particular situations or at least were evident to a lesser degree. Regarding Arab traditions, culture and perceptions of women and the patriarchal structure of the family, these women provide discussion and examples that illustrate these barriers. Participants stated:

“In my case, I didn’t consider the family to be a barrier. My family (sons, daughter and husband) encouraged me to be in a better position. It is my job to manage my time and prioritize my duties to avoid the pressure of having many tasks to do."

"Yes, I agree. Normally, leadership positions require more time and devotion than other positions, and in our culture there is dominating belief that most of women's time should be spent at home with her family. Even when you have a successful female leader, you will hear jokes that her husband must be the woman at home."

"I agree that it is not always easy. One of the examples is what happens when some husbands prevent their wives from taking leading positions for fear of how she would cope with family commitments, concerns regarding dealing with men in her field, jealousy, fear of losing control."

Although the women interviewed did not have to deal with these barriers to the same degree as other women, the participants were quite aware that these barriers existed. Several other barriers emerged from these interviews, including the idea that some women simply want "the easiest way to live," choosing easy jobs with high salaries and not necessarily leadership positions. In addition, the interviewees referenced individuals in charge of hiring who embrace the thinking behind these barriers and the lack of an encouraging environments for women in leadership positions.

Concerning religion, five participants agreed that particular interpretations of Islam create a barrier. The following participant quote illustrates this point.

"Also, some people interpret the rules of Islam based on experiences, or wrong understanding of Islam ... I know some families who refused to allow their daughter to work in some places because of the idea of working with men in the same office. That is a misconception and this is supported by some historical stories in the first stage of Islam. The women worked hand by hand with men to build the Islamic community. Some men will have different perceptions about the women who work in these places, that they are not suitable for him as a wife, and this leads the parents to prevent their daughters [from working] in the middle management.

As these quotes illustrate, the interviews confirm the findings that were reported by those leaders who completed the questionnaire.

\section{Prejudice and Unfair Treatment}

Similar to findings reported from participants' questionnaire responses, three of these leaders who were interviewed did not believe there was any prejudice or unfair treatment toward Arab women living in Qatar. This is determined in relationship to other Arab nations as the following quote illustrates: "I don't agree that there is unfair treatment especially in Qatar where women are treated fairly and with high respect." In some Arab countries, women are not allowed to even study." In addition, unfair treatment is justified by calling upon Arab culture as this quote argues: 
"There are no prejudices in Qatar. I am paid the same as a man leader. If there are some increment in his salary this is due to the high responsibilities he has. This is the nature of the Arab family."

The remaining participants indicated that there was some form of unfair treatment that is illustrated by the following quotes: "Yes, there is prejudice and unfair treatment. Some rules and regulations represent a prejudice against women in leadership positions."

"The difficult phase is getting into leadership positions where there are male rivals. However, laws in general, are not fair to women. One example is a female general manager couldn't travel to a conference because her husband did not allow her, so the police did not let her in the airplane."

The interviews support the findings from the questionnaires. That is, there are barriers that exist for Arab women living in Qatar. The existence and degree of barriers and unfair treatment strongly depend on the particular context that includes the leadership position, the family and others elements as discussed above.

\section{DISCUSSION}

These findings illustrate that there are several barriers that Middle Eastern women face as leaders, including a patriarchal society norms, customs and traditions, family barriers, traditional views of women, particular interpretations of Islam, and Qatarization. Findings from both surveys and interviews demonstrate that the majority of participants are aware of the barriers they face as Middle Eastern women in leadership positions, as well as the reasons for these barriers and the thinking that serves as the base for these barriers. An important point that surfaces in this study is that these participants have an awareness of the barriers that they face; however, there is little discussion regarding specifics of how these barriers manifest themselves in the daily lives of these women. For example, if these women face prejudice and are treated unfairly, what are the specifics of how these manifest themselves in everyday life? If their husband does not support them in a leadership position, how does this specifically play out? Further research and discussion is needed regarding this aspect of the study.

There are those participants that view the exception (a woman in a major leadership role) as the rule arguing that merit alone provides leadership positions and eradicates prejudice and unfair treatment. It can be easily argued that these individuals lack an awareness of the social, religious and cultural factors that impact and shape gender roles and leadership. Hence, these findings illustrate the importance for Middle Eastern female leaders to gain knowledge of their social reality and why things are the way they are and to critically reflect upon this reality and transform it through further action and critical reflection. They must be willing and capable of understanding their own and others' views of the world, critically reflect on these views and be open to new ways of viewing the world and acting. In the case of educational leaders, women can engage in this process and develop these skills through well-thought-out educational leadership preparation that incorporate Transformative Learning theory.

\section{LIMITATIONS}

Prior to these recommendations, it is important to consider the male role in leadership preparation. The barriers that men might face as male leaders are not addressed in this study. However, real transformation must consider the male role, their own awareness of the plight of Middle Eastern women leaders and also the barriers they place upon women. It is vital not to isolate men in the suggestions below since there will be men in leadership course and their voices and perspectives are important. It is reasonable for male students to learn the material by listening to the women in the class and to investigate their own responses to the knowledge and discussions from a male perspective. Because of the Arab culture and barriers between men and women, some assignments might need to be adjusted, but the instructor's job is to teach the material to all students and help all students make it relevant to their lives.

\section{RECOMMENDATIONS}

In order to empower women to face these barriers and become effective leaders, we argue women must be provided with the skills and opportunities to reflect upon their own beliefs, societal and 
institutional values and use these in the leadership positions they undertake. Brown ${ }^{15}$ argues that "courses designed for individuals preparing for careers as transformative educational administrators require critical thought and systematic reflection with regard to ideas, values, and beliefs surrounding social life, cultural identity, educational reform, and historical practices” (p. 89). Hence, implementing transformative learning theory to the teaching of adult Middle Eastern women in educational leadership programs will better equip women to understand why these barriers exist and how to effectively address them as leaders.

Taylor ${ }^{16}$ concludes that TLT has become the iconic educational philosophy in the field of adult education because it provides opportunities for learners to develop "a frame of reference that is more inclusive, discriminating, self-reflective, and integrative of experience" (p. 5). ${ }^{17}$ Transformative learning can be defined as:

"the process by which we transform our taken-for-granted frames of reference (meaning perspectives, habits of mind, mindsets) to make them more inclusive, discriminating, open, emotionally capable of change, and reflective so that they may generate beliefs and opinions that will prove more true or justified to guide action (pp. 7-8)."17

Transformative learning is the process of causing change in an individual's frame of reference. Brown ${ }^{15}$ argues that "transformative learning changes the way people see themselves and their world. It attempts to explain how their expectations, framed within cultural assumptions and presuppositions, directly influence the meaning they derive from their experiences" (p. 84).

There are several themes of transformative learning that are important for this context; centrality of experience, critical reflection, and rational discourse. ${ }^{18,19}$ First, centrality of experience is the starting point for TLT because people's assumptions are constructed by their subjective interpretation of experience and TLT provides opportunities for individuals to examine the experiences that shape who they are and begin to confront the biases and shortcomings in how they view the world. Second, critical reflection is at the heart of transformational learning, because people need to understand what currently exists before they can begin to understand what should exist. ${ }^{20}$ Brookfield ${ }^{21}$ defines critical reflection as focusing

"on three interrelated processes; (1) the process by which adults question and then replace or reframe an assumption that up to that point has been uncritically accepted as representing commonsense wisdom, (2) the process through which adults take alternative perspectives on previously taken for granted ideas, actions, forms of reasoning and ideologies, and (3) the process by which adults come to recognize the hegemonic aspects of dominant cultural values (p. 2)."

Critical reflection provides opportunities for what ${ }^{22}$ termed perspective transformation, "to reflect change within the core or central meaning structures through which we make sense of the day-to-dayness of our experience" (p. 4). ${ }^{23}$ Finally, a key element in TLT is rational discourse that requires a commitment to careful listening and openness to new perspectives. This demands a deeper understanding of one's own perspectives but also those of others and how each views particular issues. In summary, TLT provides opportunities for learners to examine current and past experiences, engage in critical reflection and critical assessment of their own epistemic and sociocultural assumptions and engage in rational discourse that transforms their thinking and actions. These elements emphasize the importance of developing meaning in the learning process, critically examining the existing view of the world and developing new ways of seeing and understanding our experiences and the world we live in, all important leadership skills. In what follows, the discussion integrates participants' suggestions and transformative learning theory to provide various possibilities that can be integrated into educational leadership programs and courses in order to provide opportunities for learners to gain the necessary skills needed to address and overcome the barriers they face.

\section{1) Provide a Language of Critique and Possibility}

Critical theorists like ${ }^{24,25}$ argue that students need to be given a "language of critique" and a "language of possibility." A language of critique refers to development of a theoretical vocabulary and a set of analytical skills drawn from the disciplines of sociology, critical theory and cultural studies while a language of possibility "refers to developing of a vision of a better world by bringing together theory into practice (praxis)" (p. 51). ${ }^{25}$ To provide his language, students must develop complex understanding of terms such as: hegemony, forms of knowledge, dominant and subordinate culture, 
ideology, oppositional ideologies, domination, dissimulation, legitimation, fragmentation and reification. ${ }^{1}$

\section{2) Transformative Readings and Activities}

Incorporating learners' centrality of experience is vital for TLT. This can be accomplished with materials, exercises and activities reflecting the real life experiences of learners. These must be used in ways to engage learners in critical reflection that provides opportunities for them to think beyond their own experiences. Critical reflection starts with bringing to the surface our internal pictures of the world and rigorously scrutinizing them. ${ }^{26}$ For example, a reading that introduces Arab women to the barriers they face regarding leadership can be assigned to the class. The instructor could do an exercise in class that allows learners to identify, examine and clarify their beliefs, feelings, and perspectives towards these barriers and then use a "think-pair-share" exercise to discuss in small groups feelings, beliefs, and actions regarding specific topics. Initially it might be necessary for the instructor to provide questions that spark critical reflection and promote rational discourse such as:

From your experiences, is the article accurate? Why or why not?

Are the themes of institutional, cultural, and gender oppression relevant today?

How does this knowledge personally and professional influence you?

What are the roles and issues facing female educational leaders in our schools and in our society?

What are possible alternative perspectives?

What are the presuppositions and their consequences?

Who benefits from structural arrangements and who loses?

These readings should provide learners with alternative explanations and ways of understanding.

\section{3) Critical Reflective Journals}

Brown ${ }^{15}$ argues "journaling makes the invisible thoughts visible" (p. 100). Journaling provides opportunities for adult learners to expand their awareness, make connections, engage in honest critical inquiry and self-analysis of one's own culture and allows learners to merge examination of personal and professional belief systems. ${ }^{15}$ This requires assignments that learners can reflect upon and engage and that can take the form of photos, video, interviews, movies, provocative statements, case studies, newspaper articles, documents, questions, readings and learner's individual experiences.

Learners should be asked to objectively reflect on the assumption of others and subjectively reflect on their own assumptions allowing them to understand multiple perspectives. Madsen and Tunheim ${ }^{27}$ point out that the inclusion of well-developed reflective assignments can assist women in better understandings of themselves and others, thinking differently and seeing how they can contribute to society and make a future impact and difference. Instructors or peers should respond with non-judgmental feedback, comments and critical questions. The learner should eventually examine their completed journals for patterns and themes in the content, opinions and thinking.

\section{4) Leadership Interview}

This assignment involves a one-on-one interview with an Arab woman who currently holds a position of leadership. The purpose is to help learners develop greater understandings of the complexities of being female leaders in a male-dominated Arab world. Learners select an Arab woman who is a leader and conduct a face-to-face interview centering on important issues related to Arab female

leadership. The class as a whole could develop a set of interview questions, and the instructor can add questions for learners to ask depending on previous class readings and discussions. Topics such as external and internal barriers that the leaders faced, how the barriers were overcome, how to lead men, among others, could be the center for the interview. Learners then describe their thoughts, emotional responses, what they learned from the interview, the lessons gained and how this might change their thinking or impact them as leaders. In addition, learners are asked to explain their new understandings

\footnotetext{
${ }^{1}$ To read insightful and complex definitions of these terms seepages $195-223 .{ }^{25}$
} 
and synthesize new information in light of previous experiences and knowledge and are expected to synthesize and relate this experiential knowledge to the course material.

\section{5) Case Studies and Role-Playing}

Suggested by several participants in this study, case studies cover a wide range of problems that can be presented for analysis and are based on real events or are developed on what might likely occur. The case study tells a story that usually involves a difficult relevant situation requiring a decision that needs to be resolved; however, most case studies do not have one clear solution. There are case studies available but creating an effective case study is probably worth the initial time because it can be written to meet the needs and experiences of the learners. For example, case studies can be designed which emphasize the leadership barriers for Arab women and learners can develop possible solutions and responses. Similar to case studies is the used of role-playing. This provides learners with many benefits such as memorable learning experiences, increased confidence, increased understanding of others' perspectives and learner interest, and more involvement. One possible use of role-playing might be to introduce a topic or provide a conflict and how it could be resolved using the students' background knowledge.

\section{6) Problem-posing}

Problem-posing is a teaching tool that develops and strengthens critical thinking in learners. Because adult learners bring to programs a wealth of knowledge from their personal experiences, the problemposing method builds on these experiences. In the context of Arab women in leadership, problem posing encourages learners to develop their own responses about the values and pressures of society. Auerbach ${ }^{28}$ provides several steps for problem posing as a method of teaching. Learners spend time on each step developing their thinking. The steps are as follows: describe the content, define the problem, personalize the problem, and discuss the problem.

\section{7) Dialog}

Dirkx ${ }^{23}$ argues, "dialog and learners develop awareness of structures within their society that may be contributing to inequality and oppression" (p. 3). Dialog in classrooms should be viewed as discussion that help learners' access and assess the assumptions and related consequences. Dialogue centers on inquiry and increasing understanding and is more exploratory. ${ }^{15}$ For example, the group of learners can discuss one single even and compare how different the perspectives including both male and female perspectives. Dialogue must always include rational discourse that will validate and refined learners' perspectives and engage them in dialectical relationship with each other.

\section{CONCLUSION}

It is no longer acceptable that universities simply be transmitters of knowledge, but rather they must provide learners with opportunities to become better prepared "for today's postmodern realities in all of its dynamic, permeable, interconnected complexity, but also with the promise for transformed consciousness and emancipatory understanding" (p. 148). ${ }^{12}$ In this context, in order to empower Middle Eastern women to be successful leaders, educational leadership preparation and professional development programs must seek outcomes that allow learners to become aware of their own understandings of the world and the alternative worldviews that exist and how to appropriately respond. Transformative learning as developed and applied above provides the possibility for learners to develop new knowledge and skills and build new leadership competencies and self-confidence. It provides a reflective discourse-open to alternative understandings and critically reflective of assumptions-that is a requirement for leadership, especially in this particular context.

\section{REFERENCES}

[1] Felder D, Vuollo M. Qatari women in the workforce. : RAND Qatar Policy Institute; 2008. Accessed May 10, 2013: http:// www.rand.org/content/dam/rand/pubs/working_papers/2008/RAND_WR612.pdf

[2] Hyslop L. Qatar population booms as economy grows. The Telegraph. 2010, Accessed December 30, 2012: http:// www.telegraph.co.uk/expat/expatnews/7894204/Qatar-population-booms-as-economy-grows.html

[3] Qatar National Development Strategy. 2011-2016. 2011;, Accessed December 23, 2012. http://www.google.com/url?s $a=t \& r c t=j \& q=\& e s r c=s \&$ source $=$ web \& $c d=1 \& v e d=0 C D U Q F j A A \& u r l=h t t p \% 3 A \% 2 F \% 2 F w w w . g s d p . g o v . q a \% 2 F g s d p$ vision\%2Fdocs\%2FNDS_EN.pdf\&ei=zGHZUL_AHonXrQfJtoDIAg\&usg=AFQjCNGoFGNwlihOeXZgct-rGLJUF85SRg\&si g2=-twPSQGkFYCFP2BBaDLrmQ\&bvm=bv.13,55534,169,d.bmk 
[4] Metcalfe B, Hutchings K, Cooper B. Re-examining Women's International Management Opportunities and Experiences: A Middle Eastern Perspective. In: Ibeh K, Davies S, eds. Contemporary Challenges to International Business. London: Palgrave-Macmillan; 2009.

- [5] Jamali D, Sidani Y, Safieddine A. Constraints facing working women in Lebanon: an insider view. Women In Management Review. 2005;20(8):581-594.

[6] Kazemi F. Gender, Islam and politics. Soc Res. 2000;67(2):22-34

[7] World Bank. Gender and development in the Middle East and North Africa: Women in the public sphere. Washington, DC: World Bank; 2003:8-9.

[8] Sabbagh A. Arab states: Enhancing women's political participation. Stockholm, Sweden: International IDEA; 2005.

[9] Karmi G. Women, Islam and patriarchalism. In: Yamani M, ed. Feminism \& Islam. New York, NY: New York University Press; 1996:69-85.

[10] Al-Krenawi A, Graham JR. Culturally Sensitive Social Work Practice with Arab Clients in Mental Health Settings. National Association of Social Workers; 2000. Retrieved May 10, 2013: http://www.socialworkers.org/pressroom/events/911/ alkrenawi.asp

[11] Knidri M. Women in Arab societies: The case of Morocco. Options Méditerranéennes: Serie A. Séminaires Méditerranéens. 2009;87:29-32, Accessed January 23, 2013. ressources.ciheam.org/om/pdf/a87/0080,1048.pdf.

[12] Madsen SR, Cook BJ. Transformative learning: UAE, women, and higher education. J Global Responsibility. 2010;1(1):127-148. doi:10.1108/20412561011039744.

[13] Daloz LA. Slouching toward Bethlehem. J Continuing High Educ. 1990;38(1):2-9.

[14] Cohen L, Manion L, Morrison K. Research Methods in Education. 6th ed. Oxford, UK: Routledge Publishers; 2007.

- [15] Brown KM. Leadership for social justice and equity: Weaving a transformative framework and pedagogy. Educ Admin Quart. 2004;40(1):77-108.

[16] Taylor E. An update on transformative learning theory: A critical review of the empirical research (1999-2005). Int J Lifelong Educ. 2007;26(2):173-191.

[17] Mezirow J. Learning to think like an adult: Core concepts of transformation theory. In: Mezirow J, and Associates, eds. Learning as Transformation: Critical perspectives on theory in progress. San Francisco: Jossey Bass; 2000:3-35.

[18] Cranton P. Transformative Learning in Action: Insights from practice. New Directions for Adult and Continuing Education. San Francisco, CA: Jossey Bass; 1997.

[19] Kegan R. In over our heads: The mental demands of modern life. Cambridge, MA: Harvard University Press; 1994.

[20] Giroux H. Border crossings: Cultural workers and the politics of education. New York: Routledge; 1992.

[21] Brookfield SD. Becoming a Critically Reflective Teacher. San Francisco: Jossey Bass; 1995.

[22] Mezirow J. Transformative dimensions of adult learning. San Francisco: Jossey-Bass; 1991.

[23] Dirkx JM. Transformative learning theory in the practice of adult education: An overview. PAACE J Lifelong Learn. 1998;7:1-14.

[24] Giroux H, McLaren P. Paulo Freire, postmodernism and the utopian imagination: A Blochian reading. In: Daniel JO, Moylan T, eds. Not yet: Reconsidering Ernst Bloch. London and New York: Verso Press; 1997:138-164.

[25] McLaren P. Life in schools: An introduction to critical pedagogy in the foundations of education. 5th ed. Boston: Allyn and Bacon; 2007.

[26] Senge P. The fifth discipline: The art and practice of the learning organization. NewYork: Doubleday; 1990.

[27] Madsen SR, Tunheim KA. Innovative reflection tools for developing leadership for transformation. International Leadership Association. Czech Republic: Prague; 2009.

[28] Auerbach E. Making meaning, making change: Participatory curriculum development or adult ESL literacy. Boston: University of Massachusetts Center for Applied Linguistics; 1992. Accessed May 10, 2013: http://www.tesl-ej.org/ wordpress/issues/volume1/ejo3/ejozr8/

\section{Appendix A}

1. What is the job title for your current position and how long have you been in that position?

2. How many years experience do you been in leadership positions?

3. What is the highest level of school you have completed or the highest degree you have received?

- Less than high school degree

- High school degree or equivalent (e.g., GED)

- Some college but no degree

- Associate degree

- Bachelor degree

- Graduate degree

4. What percentage (estimate) of males and females do you supervise?

5. How would you describe your leadership style?

6. Do you think there are barriers for Arab Middle Eastern women in leadership positions? If so, please identify these barriers and provide examples.

7. Do you think there are organizational and cultural barriers to Arab Middle Eastern women in leadership positions? If so, please explain and provide examples.

8. Do you think there is a prejudice about Arab Middle Eastern women's leadership abilities?

9. Do you think that Arab Middle Eastern women have experiences of being treated unfairly in leadership positions?

10. Is it more difficult to be an Arab Middle Eastern women in a leadership position than it is to be an Arab Middle Eastern man? Explain. 
Page 13 of 13

\section{Appendix B}

The following are the interview guide questions that were developed form the emergent themes from the analyzed surveys

Interview Questions

(1) From our surveys were gathered that there are several barriers to females in leadership positions in Qatar. 1) Arab Culture and Traditions 2) Families 3) Interpretation of Islam

Do you agree with these? Any examples

Can you add other barriers?

(2) About 34\% (14 respondents) indicated that there was some prejudice against women in leadership positions and 40\% (16 respondents) believed that women leaders faced some unfair treatment.

Do you agree or disagree with this? Can you provide some instances when there was prejudice or unfair treatment toward women in leadership positions.

(3) Considering the barriers and constraints on women in leadership positions, if you were preparing women for leadership positions, what courses, assignments or what could be added to program to allow them to become better leaders? 